Check for updates

Cite this: Soft Matter, 2017, 13,8651

Received 23rd August 2017 Accepted 27th October 2017 DOI: $10.1039 / \mathrm{c} 7 \mathrm{sm} 01702 \mathrm{~b}$ rsc.li/soft-matter-journal

\section{A pure magnetite hydrogel: synthesis, properties and possible applications $\dagger$}

\author{
Elizaveta I. Anastasova, (D) a Vladimir Ivanovski, ${ }^{\text {b }}$ Anna F. Fakhardo, ${ }^{a}$ \\ Artem I. Lepeshkin, ${ }^{c}$ Suheir Omar, ${ }^{d}$ Andrey S. Drozdov ${ }^{* a}$ and \\ Vladimir V. Vinogradov*a
}

\begin{abstract}
A magnetite-only hydrogel was prepared for the first time by weak base mediated gelation of stable magnetite hydrosols at room temperature. The hydrogel consists of $10 \mathrm{~nm}$ magnetite nanoparticles linked by interparticle $\mathrm{Fe}-\mathrm{O}-\mathrm{Fe}$ bonds and has the appearance of a dark-brown viscous thixotropic material. The water content in the hydrogel could be up to $93.6 \%$ by mass while volume fraction reaches $99 \%$. The material shows excellent biocompatibility and minor cytotoxic effects at concentrations up to $207 \mu \mathrm{g} \mathrm{mL} \mathrm{L}^{-1}$. The gel shows excellent sorption capacity for heavy metal adsorption such as chrome and lead ions, which is $225 \%$ more than the adsorption capacity of magnetite nanoparticles. Due to thixotropic nature, the gel demonstrates mechanical stimuli-responsive release behavior with up to $98 \%$ release triggered by ultrasound irradiation. The material shows superparamagnetic behavior with a coercivity of $65 \mathrm{emu} \mathrm{g}^{-1}$ at 6000 Oe. The magnetite gels prepared could be used for the production of magnetite aerogels, magnetic drug delivery systems with controlled release and highly efficient sorbents for hydrometallurgy.
\end{abstract}

\section{Introduction}

Magnetic gels and aerogels are fast developing areas in the materials science. Due to large specific surface areas, well-developed microstructures and excellent sorption properties, such materials find applications in different areas of industries including biomedicine e.g. concentration, storage and controlled release of different agents. They can also be used in microfluidic devices ${ }^{1}$ as oil sorbents, ${ }^{2}$ for the fabrication of microsensors and soft actuators, ${ }^{3}$ wastewater treatment ${ }^{4}$ cancer therapy, ${ }^{5,6}$ targeted drug delivery application $^{7-10}$ etc. $^{11-13}$ The vast majority of the known magnetic gels and aerogels represent multicomponent systems consisting of magnetic nanoparticles (such as magnetite) and polymers, responsible for the formation of a gel structure. ${ }^{1,14,15}$ Magnetic gels can be prepared by different approaches, such as blending methodology, when separately prepared magnetic nanoparticles (MNPs) are encapsulated into a gel in the process of polymerization. ${ }^{16}$

\footnotetext{
${ }^{a}$ Laboratory of Solution Chemistry of Advanced Materials and Technologies, ITMO University, Saint-Petersburg, 197101, Russian Federation.

E-mail:drozdov@scamt.ru,vinogradov@scamt.ru

${ }^{b}$ Faculty of Natural Sciences and Mathematics, Institute of Chemistry,

Ss. Cyril and Methodius University in Skopje, Skopje, 1000, Republic of Macedonia ${ }^{c}$ Chair of Applied Biotechnology, ITMO University, Saint-Petersburg, 197101, Russian Federation

${ }^{d}$ Institute of Chemistry, Casali Center for Applied Chemistry and Center for Nanoscience and Nanotechnology, The Hebrew University of Jerusalem, Jerusalem, 91904, Israel

$\dagger$ Electronic supplementary information (ESI) available. See DOI: 10.1039/c7sm01702b
}

Magnetic nanoparticles can be in situ synthesized in a gel matrix, and the hydrogel serves here as a reactor for the co-precipitation process. ${ }^{17}$ Since in the both methods mentioned no covalent bonds between MNPs and the hydrogel networks exist, the stability of the resultant materials cannot be guaranteed. To overcome this problem, the surface of the MNPs is modified by several functional groups serving as nano-crosslinkers, thus forming covalent coupling with the monomers being polymerized. In this way a magnetic gel with MNPs incorporated into the gel structure is formed, insuring stability of the material. ${ }^{18}$ However, this process leads to complex synthetic procedures and results in low magnetization of the final material. An alternative strategy in the production of iron oxide gels is direct gelation of iron salts in water or alcohol solutions by weak bases such as propylene oxide, tetrahydrofuran or pyridine. ${ }^{19}$ Detailed information on the gelation process investigated previously ${ }^{20}$ can be summarized as follows: weak bases act as proton scavengers to react with protons of water molecules present in the coordination sphere of a hydrated metal complex. This is followed by a nucleophilic attack on the epoxide ring, leading to ring opening, and as a result net elimination of protons from a solution occurs (eqn (1) and (2)).

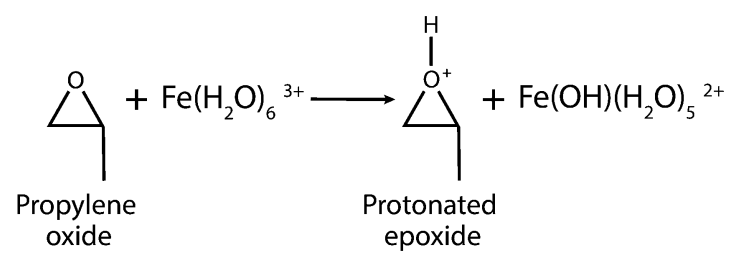




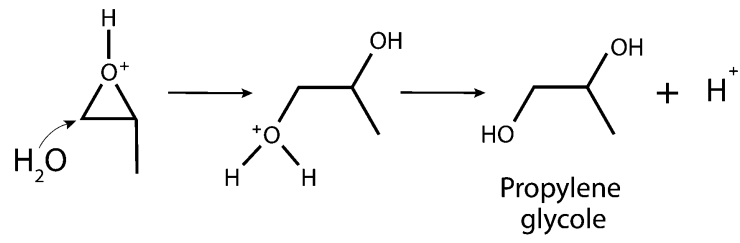

Further hydrolysis and condensation of the originally hydrated metal complex result in the formation of an iron oxide phase with $\mathrm{Fe}_{2} \mathrm{O}_{3}$ stoichiometry and a branched structure. ${ }^{21}$ This technique allows the fabrication of stable iron oxide gels, which are suitable for supercritical drying. The drawback is, however, that the materials produced using this technique consist of non-magnetic iron oxides, mainly of goethite. ${ }^{20}$ The transformation of the goethite gel into magnetic species of magnetite or maghemite requires high-temperature treatment. ${ }^{22}$ This procedure eventually leads to partial structure destruction, hence, it is unsuitable for the preparation of bio- or organically-doped composites. An alternative strategy can be a two-step procedure of nanoparticle gelation that relies on the formation of the gel structure by the stimulation of magnetite interparticle $\mathrm{Fe}-\mathrm{O}-\mathrm{Fe}$ bond formation. To do this, a stable hydrocolloid of magnetite is required. Furthermore, the nanoparticles should be thickly coated with $\mathrm{Fe}-\mathrm{OH}$ residues, which provides the formation of interparticle bonds and supports the gel structure. However, despite the attractiveness of this possibility, this path is complicated due to the poor colloid stability of the unmodified magnetite nanoparticles, and has not been described in the literature yet. In this article we describe, for the first time, the pure magnetite gel (ferria gel) prepared by the direct gelation of a magnetite hydrosol. The gelation of the magnetite hydrosol occurs under the influence of a propylene oxide proton scavenger and results in the formation of a dense and highly magnetic gel. The gel composition, the nature of the gelation process and the gel structure organization have been investigated employing Raman and IR spectroscopy. The physico-chemical parameters of the materials obtained, as well as their sorption properties against heavy metal ions and organic dyes, are also described.

\section{Experimental details}

\subsection{Materials}

Chemicals. Iron(II) chloride tetrahydrate $\geq 98.5 \%$, iron(III) chloride hexahydrate $\geq 99 \%$ potassium bichromate $\geq 98.5 \%$, lead acetate $\geq 98 \%$, aqueous solution of ammonia $\geq 27.5 \%$, eosin $Y$, alizarin $\mathrm{S}$, methylene blue, propylene oxide, and thiazolyl blue tetrazolium bromide (MTT, $\geq 97.5 \%$ ) were obtained from Sigma-Aldrich. Dimethyl sulfoxide (DMSO) was obtained from VWR. Phosphate buffered saline (PBS) tablets were purchased from Gibco.

Preparation of a magnetite hydrosol (designated as magnetite NPs). A stable magnetite hydrosol was prepared by an ultrasonically (US) assisted co-precipitation method as described in ref. 23. The as-prepared hydrosol was concentrated in a rotary evaporator at a residual pressure of $50 \mathrm{mbar}$ and a temperature of $40{ }^{\circ} \mathrm{C}$ to the final magnetite mass fraction of $10 \mathrm{wt} \%$. The so-obtained hydrosol can be diluted to a desired concentration by deionized water.
Preparation of the ferria gel (designated as ferria gel). $3 \mathrm{~mL}$ of magnetite hydrosol (2-10 wt\%) was mixed with 0-3 mL of propylene oxide in a plastic tube in one step under room conditions. The mixture was stirred for 5 minutes using a vortex stirrer (2500 rpm), and left for aging. Gel formation was observed after 6 to 18 hour period.

Entrapment of organic molecules into the ferria gel. For the entrapment of organic dyes, such as methylene blue, eosin Y and alizarin $\mathrm{S}, 3 \mathrm{~mL}$ of a freshly prepared magnetite hydrosol (10 wt\%) was mixed with $300 \mathrm{mg}$ of a dye, and after mixing $3 \mathrm{~mL}$ of propylene oxide were added under vigorous stirring. The mixtures were afterward left for 6 hours aging.

\subsection{Methods}

Study of the sorption properties of the gel. Stock solutions of chromium $\left(\mathrm{Cr}^{6+}\right)$ and lead $\left(\mathrm{Pb}^{2+}\right)$ in double distilled water were prepared with a concentration of $200 \mathrm{mg} \mathrm{L}^{-1}$. The $\mathrm{pH}$ of the working solutions was maintained using dilute $\mathrm{HNO}_{3}(0.1 \mathrm{M})$. $150 \mathrm{mg}$ of the ferria gel was added to $15 \mathrm{~mL}$ of the working solutions and shaken at room temperature for 24 hours. Following magnetic separation, the concentration of the ions was determined using the colorimetric method. The amount of the sorbed ions was calculated from the difference in their content in solutions before and after sorption. The regeneration of the gels after adsorption was performed by washing them using $20 \mathrm{~mL}$ of $0.005 \mathrm{M} \mathrm{NaOH}$ (for $\mathrm{Cr}$ ) and $0.01 \mathrm{M} \mathrm{HNO}_{3}$ (for $\mathrm{Pb}$ ) solutions and agitating at $25{ }^{\circ} \mathrm{C}$ for $30 \mathrm{~min}$.

Study of the dye release from the pores. To study the kinetics of the dye release, $100 \mathrm{mg}$ of the organically doped gel were placed in a cuvette and $2 \mathrm{~mL}$ of water were added. The increase of optical density was measured in kinetic mode using the colorimetric method.

MTT assay. To evaluate the cytotoxicity of ferria gel human mesenchymal stem cells (MSCs) and tumor HeLa cell lines (Biolot, St. Petersburg, Russia) were maintained in DMEM with $1 \mathrm{~g} \mathrm{~L}^{-1}$ of glucose and Eagle's medium (Biolot) respectively supplemented with $10 \%$ fetal bovine serum (Gibco) and $50 \mu \mathrm{g} \mathrm{mL}$ gentamycin (Biolot) at $37{ }^{\circ} \mathrm{C}, 5 \% \mathrm{CO}_{2}$. Cells in the logarithmic phase of growth were plated $\left(5-10 \times 10^{3}\right.$ well) into 96-well plates overnight and then treated for $72 \mathrm{~h}$ with ferria gel resuspended directly in the culture medium at final concentrations of $17-270 \mu \mathrm{g} \mathrm{mL}{ }^{-1}$. The volume of the added ferria gel from the stock gel was $<10 \%$ from the total volume of the culture medium in the wells. After the completion of cell exposure, the medium with particles was discarded, and $200 \mu \mathrm{L}$ MTT (3-(4,5-dimethylthiazol-2yl)-2,5-diphenyltetrazolium bromide; $0.5 \mathrm{mg} \mathrm{mL}^{-1}$ ) solution in PBS was added to each well and kept for $1.5 \mathrm{~h}$ at $37{ }^{\circ} \mathrm{C}, \mathrm{CO}_{2}$. The MTT solution was aspirated, and formazan granules were dissolved in $200 \mu \mathrm{L}$ DMSO. Optical density was measured at $570 \mathrm{~nm}$ on a Tecan Infinite 50 spectrophotometer. Cell viability was calculated as the percentage of optical densities in wells with each concentration of ferria gel normalized to the optical density of untreated cells $(100 \%)$.

Characterization methods. The surface area, pore volume and pore size distribution were investigated using Quantachrome Nova 1200 e by nitrogen adsorption at $77 \mathrm{~K}$ and analyzed using the BET and BJH equations. Prior to analysis, all samples were 
degassed at $110{ }^{\circ} \mathrm{C}$ for 4 hours. Zeta potential was measured using a Photocor Compact- $Z$ analyzer. The crystalline phase and crystallinity of the samples were measured by X-ray diffraction (Bruker D8 Advance) using $\mathrm{Cu} \mathrm{Ka}$ radiation $(\lambda=1.54 \AA)$. The samples were scanned for $2 \mathrm{~h}$ at a rate of 0.5 degrees per minute. For SEM analysis the samples were dried in vacuo for $1 \mathrm{~h}$ and examined using a Tescan VEGA 3 electron microscope. The Raman spectra were recorded using the $633 \mathrm{~nm} \mathrm{He}-\mathrm{Ne}$ laser line on a Horiba Jobin-Yvon MicroRaman 300 spectrometer. The laser power on the samples employed was $0.030 \mathrm{~mW}$ and $0.344 \mathrm{~mW}$, with $300 \mathrm{~s}$ and $120 \mathrm{~s}$ exposition per diffraction window, respectively. In all the measurements, a $50 \times$ Olympus lens, a hole of $500 \mu \mathrm{m}$, a slit of $100 \mu \mathrm{m}$ and a diffraction grid with 1800 grooves per mm were employed. IR measurements were performed in transmission and ATR mode. For transmission measurements, the KBr pellet technique was used. The KBr powder (IR grade Sigma Aldrich) was dried at $150{ }^{\circ} \mathrm{C}$ for 24 h. 32 scans for the background and the sample measurement was used. The IR-ATR spectra were recorded on a Perkin-Elmer FT-IR System 2000 using High Temperature GoldenGate ATR accessory (product of Specac), equipped with a diamond ATR crystal. The ZnSe lenses allowed the ATR spectrum to be recorded as low as $520 \mathrm{~cm}^{-1}$. The spectra of the samples and the background were recorded using 64 scans. Both the transmittance and ATR spectra of the samples were recorded against the air/ $\mathrm{N}_{2}$ as a background (the sample compartment and detector were purged with $\mathrm{N}_{2}$ with $99.999 \%$ purity). The samples for transmission electron microscopy (TEM) were obtained by dispersing a small probe in ethanol to form a homogeneous suspension. Then, a suspension drop was coated on a copper mesh covered with carbon for a TEM analysis (FEI TECNAI G2 F20, at an operating voltage of $200 \mathrm{kV}$ ). Spectrophotometric measurements were carried out using an Agilent Cary HP 8454 Diode Array spectrophotometer with TEC. Viscosity was determined using a Fungilab rotational viscometer. In order to measure the viscosity gelation was carried out in a cuvette with a spindle immersed in it. All rheological measurements were carried out using a RN 4.1, RHEOTEST Medingen $\mathrm{GmbH}$, Germany at $20^{\circ} \mathrm{C} .8 \mathrm{~mL}$ of the ferria gel was loaded to the rheotest with a $1.9 \mathrm{~cm}$ stainless steel cylinder and an indenter of $1.2 \mathrm{~cm}$. The viscosity of the sample was measured as a function of the shear rate in a range from 1-8 s $\mathrm{s}^{-1}$ (in the forward direction). To assess the ability of the sample to reconstruct the structure after mechanical action, the sample remained at rest for 15 minutes, and then again was subjected to mechanical loads from 8 to $1 \mathrm{~s}^{-1}$ (in the opposite direction). We also carried out studies to obtain a storage modulus $\left(G^{\prime}\right)$ and a loss modulus $\left(G^{\prime \prime}\right)$ at frequencies from 0.6 to $7 \mathrm{rad} \mathrm{s}^{-1}$.

\section{Results and discussion}

\subsection{Synthesis of the ferria gel}

For the synthesis of ferria gels we used a stable magnetite hydrosol, the preparation of which was described in our previous work..$^{23}$ Shortly, the stable magnetite hydrosol was synthesized using US-assisted and co-precipitation methods. The synthetic
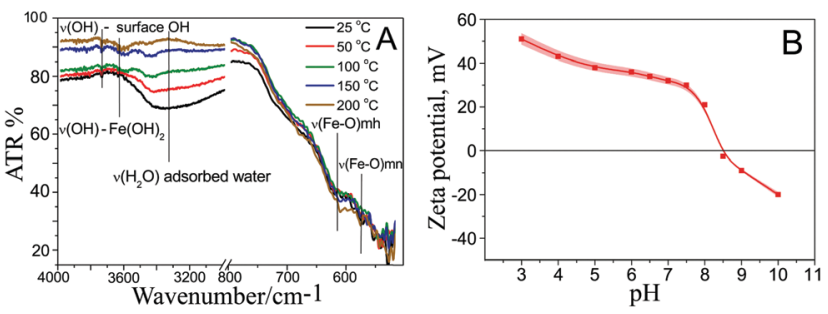

Fig. 1 Characterization of a magnetite hydrosol. (A) IR-ATR spectra of the ferria sol in the frequency range of water and $\mathrm{OH}$ vibrations recorded at different temperatures. Dehydration allows distinguishing between the different $\mathrm{OH}$ vibration modes and the vibration modes of the adsorbed $\mathrm{H}_{2} \mathrm{O}$ molecules present at the sample surface. The bands originating from the presence of magnetite $(\mathrm{mn})$ and maghemite $(\mathrm{mh})$ are also given for comparison. (B) Zeta potential and isoelectric point (8.0) of the magnetite hydrosol.

procedure employs a non-stoichiometric $\mathrm{Fe}^{2+} / \mathrm{Fe}^{3+}$ ratio with the US-mediated Shikorr reaction and results in MNPs which are characterized with excellent colloidal stability of water media provided by a highly-positive zeta potential $(+36 \mathrm{mV}$ at $\mathrm{pH} 7$ ). The investigation of the MNPs using ATR-IR spectroscopy ${ }^{23}$ shows the presence of $\mathrm{Fe}-\mathrm{OH}$ groups originating from both magnetite and $\mathrm{Fe}(\mathrm{OH})_{2}$ on the NP surface (Fig. 1A). The presence of $\mathrm{OH}$ groups on the surface is enough to shift the isoelectric point of the material to a basic pH (Fig. 1B). On the other hand, the presence of $\mathrm{OH}$ groups on the MNP surface makes interparticle bonding and, thus, gel formation possible.

Magnetite gels were produced by the addition of propylene oxide to a magnetite hydrosol. The process of gelation was an exothermic reaction resulting in a dark-brown gelly magnetic material. The kinetics of the gelation process mainly depends on the reagent ratio and can last from 6 to almost 18 hours. For the initial experiments, equal volumes of propylene oxide and magnetite hydrosols having different magnetite mass fractions were mixed. Further, a gel point was determined as a point where the solution ceased to discernibly flow under the influence of gravity. The measurements were also carried out using a rotary viscometer. While the gelation of the hydrosol is mediated only by interparticle interaction, the volume fraction of MNPs plays a key role in the formation of a gel network (Fig. 2A). The gelation process was observed for the hydrosol with $10 \%$ mass fraction, which corresponds to 1 vol\% of magnetite in the gel. Within the period of 6 hours, the viscosity of the samples increased up to $4670 \mathrm{mPa}$ s, and a gel monolith was formed. It should be noted that because of the thixotropic nature, the gel structure is irreversibly destroyed during the measurement, and further gelation did not occur. Systems with a lower volume fraction of magnetite show minor viscosity growth and remain in a liquid form even after 24 hours from the beginning of the process.

Another important parameter influencing the gelation kinetics is the [Pr.ox. $] /\left[\mathrm{Fe}_{3} \mathrm{O}_{4}\right]$ ratio (Fig. $2 \mathrm{~B}$ ). Different molar ratios were tested starting from the maximal one, which corresponds to a homogeneous system (a molar ratio of $40: 1$ and a volume ratio of $1: 1$ ). This point corresponds to the partial miscibility, with the second liquid phase forming above this ratio. The increase of the 

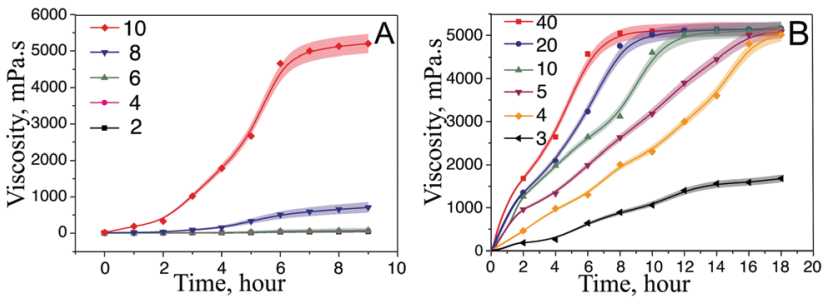

Fig. 2 Gelation curves of the magnetite hydrosol. (A) Gelation of hydrosols with varying magnetite mass fractions. Lines for 2, 4 and $6 \mathrm{wt} \%$ are merged due to equality of the viscosity value. (B) Gelation of the hydrosol with 10 wt\% and different [Pr.ox.] $/\left[\mathrm{Fe}_{3} \mathrm{O}_{4}\right]$ ratios.

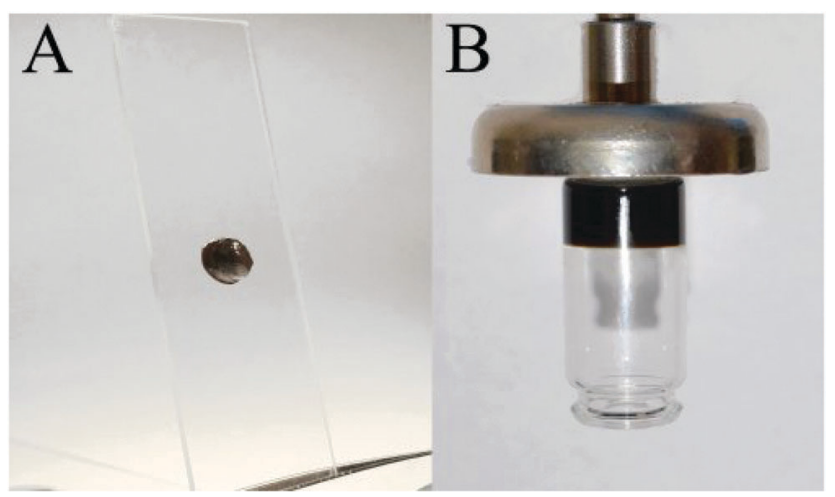

Fig. 3 Visual appearance of the synthesized gel. (A) A drop of ferria gel does not flow down from the glass. (B) The vial with ferria gel is attracted by a magnetic field and lifted into the air.

propylene oxide molar ratio leads to the acceleration of the rate of gelation, but has a minor effect on the final gel viscosity. For the maximal Pr.Ox: $\mathrm{Fe}_{3} \mathrm{O}_{4}$ ratio, the full gelation occurs within 6 hours, the decrease of the propylene oxide fraction makes the gelation process slower until it reaches the lower limit with a volume ratio of $4: 1$. A further decrease in the Pr.Ox. content leads to a partial viscosity gain, but also hinders the gel formation. This can be attributed to the fact that theoretically a single propylene oxide molecule forms a single interparticle bond and prevents two separate nanoparticles to form an interparticle bond. As a result, no gel structure is formed.

We have synthesized ferria gel with equal volumes of propylene oxide and magnetite sol. It appears as a stable dark brown gel with magnetite content (solid phase) being $6.4 \mathrm{wt} \%$ and $1 \mathrm{vol} \%$ of the solid phase, while 99 vol\% was occupied by the solvent. Due to the high viscosity a drop of the ferria gel does not flow under the influence of gravity and remains still on the glass slide when put in a vertical position (Fig. 3A). The high mass fraction of the magnetite phase ensures good magnetic properties of the material, and it is readily attracted by an external magnetic magnetic field, as presented in Fig. 3B.

\subsection{Rheological properties of the ferria gel}

The rheological properties of the ferria gel were obtained from the characteristic curves of the dependence on the viscosity of shear rate in the forward direction (upon structural breakdown) and in the reverse direction (after 15 minutes at rest). Also the
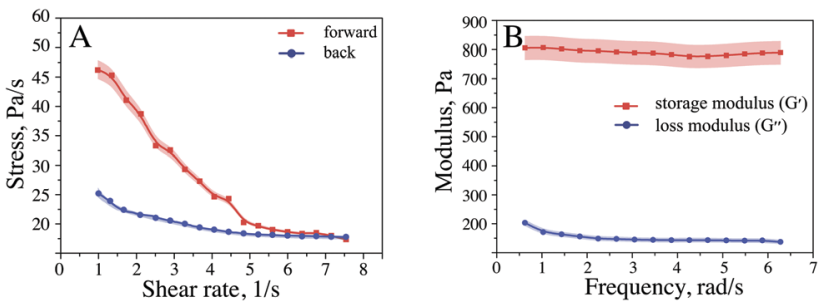

Fig. 4 Rheological properties of the ferria gel (A) viscosity - shear rate dependence; (B) storage and loss modules of ferria gel.

storage modulus $\left(G^{\prime}\right)$ and the loss modulus $\left(G^{\prime \prime}\right)$ at different frequencies were measured. The complex study of the rheological properties of the sample makes it possible to characterize its resistance to mechanical action and the ability to reconstruct the structure after predetermined time. The sample demonstrated a nonlinear viscosity dependence of the shear rate. Apparently, the gel shows much higher viscosity at initial shear rates than at high shear rates (up to $8 \mathrm{~s}^{-1}$ ) (Fig. 4A). A study of the viscosity of the ferria gel in the reverse direction (at a shear rate of 8 to $1 \mathrm{~s}^{-1}$ ) showed that the sample has weakly expressed thixotropic properties which can be seen from the lower resistance of the destroyed gel. The sample demonstrated only a partial restoration $(45 \%)$ of the structure after the sample was kept at rest. Fig. 4B shows the dependence of the moduli $G^{\prime}$ (storage modulus), $G^{\prime \prime}$ (loss modulus) from 0.6 to $7 \mathrm{rad} \mathrm{s}^{-1}$. The choice of such modes is due to the low viscosity of the initial gel, as well as the instability of the system, which results in a higher level of module $G^{\prime}$ compared to module $G^{\prime \prime}$. The storage modulus of the sample shows a lower frequency dependence than the loss modulus. The module remains almost unchanged with increasing frequency, which indicates high elasticity at minimum loads, while the dependence is almost linear. The module $G^{\prime \prime}$ varies nonlinearly as a function of frequency, which is caused by the loss of stability of the gel structure. Due to fragility of the magnetite gel structure the material demonstrates only limited injectability. ${ }^{24}$ When pushed through a syringe needle only partial gel structure recovery (up to $30 \%$ after $30 \mathrm{~min}$ ) was observed (Fig. 1S, ESI $\dagger$ ).

The structure and properties of the materials synthesized were subjected to a detailed investigation aimed to describe the nature of the gel structure and its organization. To determine specific analytical signals, a dried magnetite xerogel was compared with a dried magnetite hydrosol.

\subsection{Characterization of the ferria xerogel}

The ferria gel was dried under a vacuum to form a highly porous xerogel. In contrast to dried nanoparticles which form thin mesoporous films, dried xerogels are low-density magnetic bulks (Fig. 5A and D). SEM (Fig. 5B and E) and TEM (Fig. 5C and F) images show the difference in the microstructure of the dried hydrosol and gel. The latter one has a more porous structure and a developed nanoarchitecture originating from the gel structure, as single-nanoparticle chains can be clearly seen.

The analysis of textural properties by low-temperature nitrogen physisorption (Fig. 6) proves the differences in the microarchitecture observed (Fig. 5) with the distinctive results for the dried hydrosol 

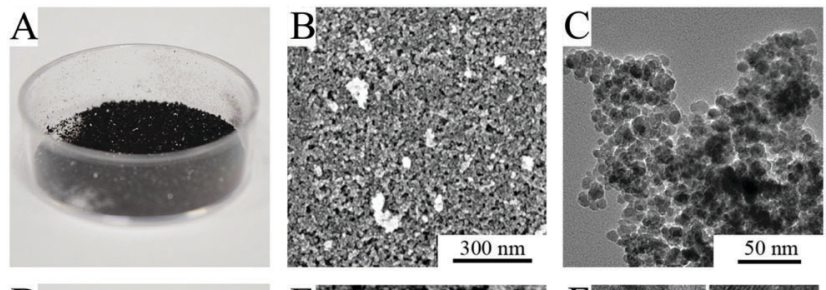

$\mathrm{D}$
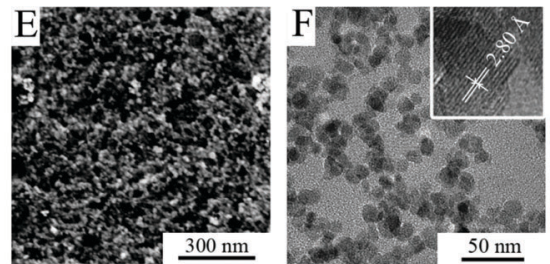

Fig. 5 Dried magnetite hydrosol and ferria gel. Upper picture line represents visual appearance (A), SEM image (B) and TEM image (C) of a dried magnetite hydrosol. Bottom picture line (D-F) present the same characteristics, but of the dried ferria gel.
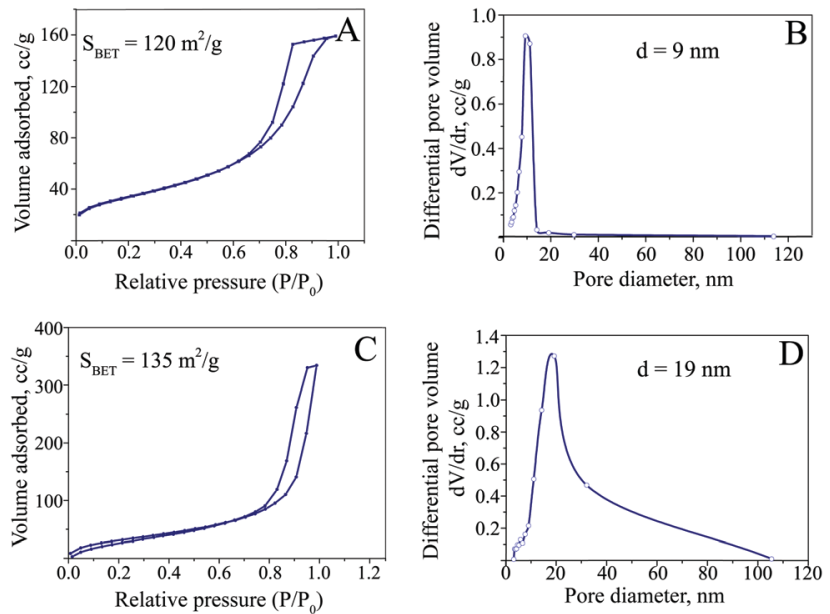

Fig. 6 Characterization of the samples by low-temperature physisorption. Nitrogen adsorption-desorption isotherms of the dried hydrosol (A) and xerogel (C). Mesopore size distributions of dried hydrosol (B) and xerogel (D) calculated using the BJH method.

and gel. The analysis of sorption curves using the BET method indicates specific surfaces of $135 \mathrm{~m}^{2} \mathrm{~g}^{-1}$ for the ferria gel sample and $120 \mathrm{~m}^{2} \mathrm{~g}^{-1}$ for the magnetite hydrosol. The comparison of other textural characteristics, however, shows even more significant difference between the two materials. The desorption branch analysis of the isotherm shows almost a 2 -fold increase of the average pore diameter and the specific pore volume for the dried xerogel compared to the hydrosol: $19 \mathrm{~nm}$ and $0.53 \mathrm{~cm}^{3} \mathrm{~g}^{-1}$ compared to $9.1 \mathrm{~nm}$ and $0.23 \mathrm{~cm}^{3} \mathrm{~g}^{-1}$, respectively. Since the specific pore volume is the function of packing and the particle size, it can be concluded that the structure formed is close to the dense sphere packing in the case of the dried magnetite hydrosol. On the other hand in the case of the dried xerogel the porosity exceeds 0.66 due to the partial preservation of the gel structure upon drying.

The X-ray diffractogram analysis of the dried ferria gel is similar to the one of the magnetite crystal lattice (compared to
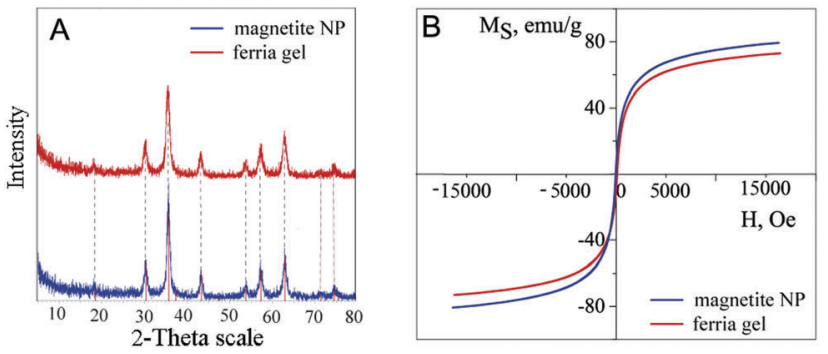

Fig. 7 (A) X-ray diffraction patterns of the samples show almost identical signals for magnetite NPs and the ferria gel (compared to JCPDS file No. 19-0629: red lines). (B) The magnetization curves of magnetite NPs and the ferria xerogel showing superparamagnetic behavior and high magnetization values.

JCPDS file No. 19-0629) and is identical to the X-ray diffractogram of the magnetite hydrosol sample (Fig. 7A). This can be attributed to the fact that the crystal lattice of the nanoparticles composing the gel is not affected during the gelation process, so the gel consists of highly crystalline nanoparticles. The Scherrer equation solution gives a $10 \mathrm{~nm}$ crystallite diameter for both the ferria gel and the hydrosol, which proves the idea that the nanoparticles themselves are unaffected by a gelation agent. The magnetization curves of the dried gel samples show the superparamagnetic behavior and high coercivity of the materials valued at 65 emu g $^{-1}$ what is close to the bulk magnetite ${ }^{25}$ (Fig. 7B).

\subsection{Magnetite gel organization}

To address the question of magnetite gel organization, Raman, IR absorbance and ATR spectra of the samples were recorded and analyzed. For the structure determination, the spectra of magnetite nanoparticles were compared with the spectra of the dried ferria gel. Magnetite, at room temperature, crystallizes in the cubic space group $F d 3 m\left(\mathrm{O}_{\mathrm{h}}^{7}\right)$, and possesses 14 atoms per asymmetric unit. According to the group-theoretical analysis it gives rise to $4 \mathrm{IR}$ vibrations of $\mathrm{T}_{1 \mathrm{u}}$ symmetry (i.e. triply degenerated vibrations) and 5 modes with symmetries $\mathrm{A}_{1 \mathrm{~g}}+\mathrm{E}_{\mathrm{g}}+3 \mathrm{~T}_{2 \mathrm{~g}}$ responsible for the appearance of Raman bands. ${ }^{26}$ The literature data indicate that a broad Raman band characteristic of magnetite, appearing at $670 \mathrm{~cm}^{-1},{ }^{27-29}$ is assigned to $\mathrm{A}_{1 \mathrm{~g}}$ type vibration. ${ }^{26}$ The Raman spectra of the samples using two different laser powers and exposition times are presented in Fig. 8. Magnetite can easily change to maghemite and further to hematite upon increasing the
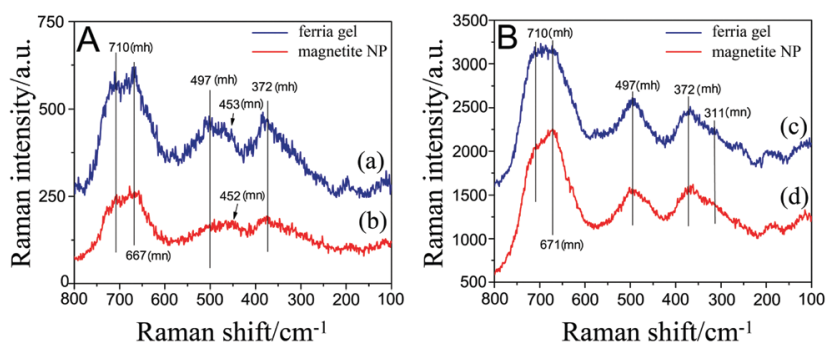

Fig. 8 Raman spectra of the ferria gel and magnetite NPs recorded at a laser power of (A) $0.030 \mathrm{~mW}$ and exposition per diffraction window of $300 \mathrm{~s}$ and $(\mathrm{B}) 0.344 \mathrm{~mW}$ and $120 \mathrm{~s}$. ( $\mathrm{mn}$ ) refers to band assigned to magnetite, while (mh) to maghemite. 
laser irradiation power. ${ }^{23,27}$ Our previous investigation ${ }^{28}$ showed that the spectra of nano-magnetite can be safely recorded using the laser powers of $0.030 \mathrm{~mW}$, while at powers of $0.344 \mathrm{~mW}$ it is partially converted to maghemite. In the latter case, bands characteristic of maghemite with maxima around 704, 499 and $360 \mathrm{~cm}^{-1}$ appear. $^{23,27,28}$

As can be concluded from the Raman spectra, the surface of magnetite NPs is partially oxidized to maghemite. It can also be seen from Fig. 8B that upon increasing the power of the laser, structural changes towards maghemite formation occur; the band at $710 \mathrm{~cm}^{-1}$ characteristic of maghemite gets even in intensity with the $667 \mathrm{~cm}^{-1}$ band characteristic of magnetite ${ }^{27}$ for the magnetite gel sample. Moreover, the band at $497 \mathrm{~cm}^{-1}$ starts to become more pronounced. On the other hand the band that appears at $453 \mathrm{~cm}^{-1}$, which can be assigned to the $\mathrm{T}_{2 \mathrm{~g}}$ mode in the spectra of pure magnetite (Fig. 8A), is no longer visible after higher power irradiation (Fig. 8B). Although earlier studies show that MNPs obtained through gelation of $\mathrm{FeCl}_{3}$ assisted by propylene oxide goes through the formation of goethite, no trace of this iron oxyhydroxide could be detected in our case. The Raman spectrum of goethite is characterized by a strong Raman band at $385 \mathrm{~cm}^{-1},{ }^{29}$ which cannot be undoubtedly recognized on the background of the broad maghemite/magnetite band at $372 \mathrm{~cm}^{-1}$ (Fig. 8).

IR absorbance and ATR considerations shed more light on the structure of the investigated samples. The IR absorbance spectra of the magnetite specimens are presented in Fig. 9. The bands due to water adsorption, (but probably also $\mathrm{OH}$ groups on the sample surface) are visible in both specimens (Fig. 9A) through the presence of a broad band in the region from 3600 to $3100 \mathrm{~cm}^{-1}$ and a band with a maximum at $1630 \mathrm{~cm}^{-1}$. They are assigned to the stretching and bending modes of the $\mathrm{HOH}$, respectively. What can also be observed is an inclined baseline, which appears because of the strong scattering of the samples. The bands due to the $\mathrm{Fe}-\mathrm{O}$ vibrations are presented in Fig. 9B. The band at $574 \mathrm{~cm}^{-1}$ originates from the $\mathrm{T}_{1 \mathrm{u}}$ phonon because of the presence of magnetite. ${ }^{30}$ The band at $632 \mathrm{~cm}^{-1}$ is due to the presence of maghemite, ${ }^{27,30}$ while the band at $712 \mathrm{~cm}^{-1}$ is assigned to $\mathrm{Fe}(\mathrm{III})-\mathrm{O}$ vibrations, with the octahedral sites Fe(II) being oxidized to Fe(III) and forming non-stoichiometric Fe(III) oxyhydroxide. ${ }^{30}$ The band at $445 \mathrm{~cm}^{-1}$ appears in the reported IR spectrum of magnetite ( $c f$. Fig. 9 in ref. 27), although not assigned. This band is also present in the IR
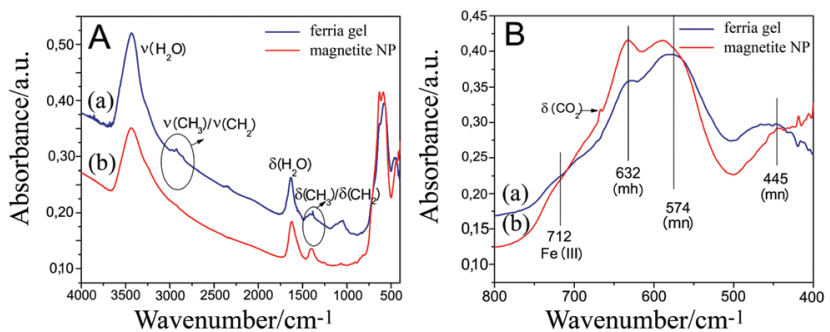

Fig. 9 IR absorption spectra of ferria gel and magnetite NPs. Panel (A) shows spectra in the whole mid-IR region, while panel $(B)$ the bands due to vibrations of the Fe-O network. absorbance spectrum of MNP sol dried particles. However, apart from this band, which lowers its intensity, there is another band in the dried ferria gel sample, almost overlapped with the first one, and with a maximum at $462 \mathrm{~cm}^{-1}$. This band, according to ref. 27 , is characteristic of hematite. If present, goethite can be recognized through its characteristic sharp and intense bands at 894 and $799 \mathrm{~cm}^{-1} \cdot{ }^{31}$ However, even after closer inspection of the spectra presented in Fig. 9A, no such bands could be spotted.

\subsection{Nature of particle-to-particle interaction}

As was noted earlier, the surface of stable magnetite NPs is covered with $\mathrm{OH}$ groups that play a key role in the NP colloidal stability and allow interparticle $\mathrm{Fe}-\mathrm{O}-\mathrm{Fe}$ bond formation, with water molecules appearing as a leaving group. In order to conduct this process, propylene oxide can be used as a proton acceptor. Propylene oxide is widely used for the gelation of inorganic salts, and its mechanism of action is well-known: after oxirane-ring oxygen being attacked by a proton from an inorganic aquacomplex, nucleophilic $\mathrm{S}_{\mathrm{N}} 2$-attack occurs on one of the carbons in the cycle, resulting in epoxide ring opening. Inorganic aquacomplexes can undergo further hydrolysis and condensation to form condensed oxide species and a gel network. If the same reaction is taking place on the magnetite NP sol, where an $\mathrm{Fe}-\mathrm{OH}$ layer is present on the NP surface, the process goes through the same mechanism: propylene oxide triggers the process in which the iron(II) ion forms Fe-O-Fe bonds, ending up the formation of the porous solid ferria gel (Fig. 10). It is then of interest to search for the formation of some kind of iron oxide "glue" in the ferria gel and to compare it with the composition of the magnetite NPs to underline the difference between them.

One of the differences between the xerogel and the dried magnetite hydrosol sample was already detected in the absorbance IR spectra of the two samples, namely the shift of the band from 455 to $462 \mathrm{~cm}^{-1}$ as an indication of the formed hematite, which should be further proved. In order to do so, it is possible to subtract one spectrum from another and observe the difference spectrum. The difference spectrum can show the components present in excess in both spectra. However, the normalization of the spectra is needed in order to subtract spectra that were recorded from the samples containing different amounts of components. One method to do that is to find a band in the spectrum whose integral intensity can be correlated with the concentration of the investigated sample. Since magnetite is the basic constituent of the investigated samples, we concentrated our efforts on isolating bands inherent to magnetite. For that purpose, we performed the baseline correction, deconvolution

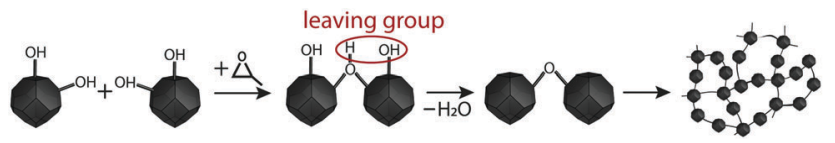

Fig. 10 Mechanism of formation of the ferria gel. Propylene oxide acts as a proton scavenger, promoting interparticle $\mathrm{Fe}-\mathrm{O}-\mathrm{Fe}$ bond formation. Subsequent cleavage of water as a leaving group leads to establishment of covalent bridges and growth of the gel structure. 

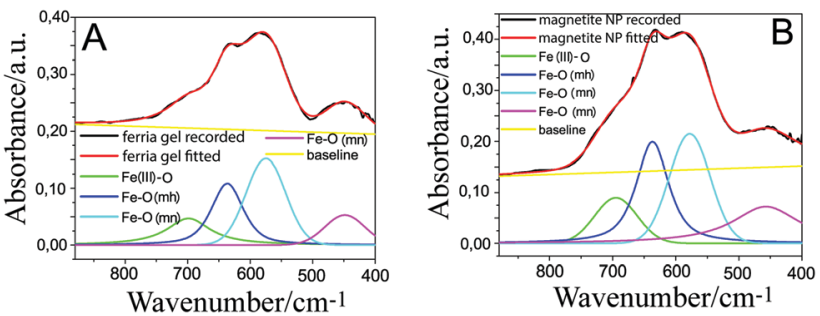

Fig. 11 Recorded and base line corrected, fitted and deconvoluted spectra of: (A) ferria gel and (B) magnetite NPs.

and curve fitting analysis of the absorbance spectra for the two samples in question (ferria gel and magnetite NPs) in the region where $\mathrm{Fe}-\mathrm{O}$ vibrations give the IR bands (Fig. 11).

The fitting was performed using the GRAMS software package ${ }^{32}$ employing the four most prominent bands assigned in Fig. 9B. The values of the frequencies and integrated intensities of the $\mathrm{Fe}-\mathrm{O}(\mathrm{mn})$ band (the most intense in the spectra) for the two specimens are: magnetite NPs $\left(575 \mathrm{~cm}^{-1}, 12.03922\right)$ and ferria gel $\left(578 \mathrm{~cm}^{-1}, 17.56348\right)$. The so-obtained integrated intensity of the magnetite NP sample was used for the normalization of the intensities of the gel sample spectra given in Fig. 11A. Afterwards the magnetite NP spectrum was subtracted from the so obtained normalized spectra of the ferria gel. The results of the subtraction are presented in Fig. 12.

From the difference spectra shown in Fig. 12a two broad positive maxima can be observed at $544 \mathrm{~cm}^{-1}$ and $477 \mathrm{~cm}^{-1}$, which originate from a $\mathrm{Fe}_{2} \mathrm{O}_{3}$ structure. Literature data ${ }^{27}$ indicate that hematite shows two strong and broad bands around

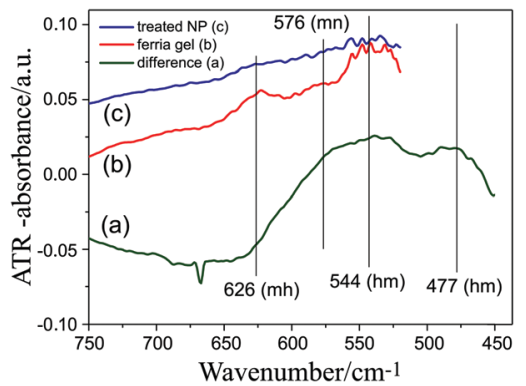

Fig. 12 Difference spectra: (a) ferria gel - magnetite NPs. IR-ATR spectra converted to absorbance and ATR corrected: (b) ferria gel, (c) magnetite NPs. ( $\mathrm{hm}),(\mathrm{mh})$ and $(\mathrm{mn})$ are labels indicating bands due to the presence of hematite, maghemite and magnetite, respectively.
$560 \mathrm{~cm}^{-1}$ and $470 \mathrm{~cm}^{-1}$. It can be then supposed that the linkage that occurs between magnetite particles is through the formation of a hematite network. Another interesting fact is the similarity between these difference absorbance spectra and the IR-ATR spectra of the ferria gel and magnetite sol dried samples (that were corrected for the penetration depth). The maxima and minima of the band positions in the difference spectrum Fig. 12(a) are close to the ATR ferria gel spectrum Fig. 12(b) but not to the recorded absorbance spectra shown in Fig. 9B. The similarity between ATR and difference spectra can be explained through the fact that ATR probes the surface of the sample. Since the hematite network dominates the surface of the magnetite nanoparticles which are embedded in it, the ATR spectra are dominated by hematite bands. These bands are almost invisible in the case of the magnetite NP sample (Fig. 12(c)). In order to obtain some quantitative information on the composition of the iron oxides present in the ferria gel and magnetite NP samples, we used the information for the integral intensities of the bands originating from the magnetite and maghemite, and found their ratio (Table 1).

The table shows the relative composition of the ferria gel and the magnetite NP sample through the content of maghemite and magnetite calculated using the integrated intensities of the corresponding bands presented in Fig. 11. If the sample thickness is different (due to the different $\mathrm{KBr}$ pellet thicknesses of the gel and magnetite NP samples), then the integrated area ratio between 636 and $575 \mathrm{~cm}^{-1}$ bands of the gel and 637 and $578 \mathrm{~cm}^{-1}$ bands of the magnetite NPs samples should be equal, since the extinction coefficients of the respective bands (assigned to maghemite or magnetite) are the same in both samples. However, these ratios are 0.69176 and 0.92987 , respectively. This actually means that the content of maghemite and magnetite is different in both samples, with about $34 \%$ larger content of magnetite in the ferria gel sample. This is the reason why a negative minimum appears for maghemite (Fig. 12(a)). It has to be kept in mind though that the band assigned to magnetite at $575 \mathrm{~cm}^{-1}$ largely overlaps with the band at $544 \mathrm{~cm}^{-1}$ which was assigned to a possible hematite presence in the gel sample. Thus, it might appear that the formed hematite linker in the ferria gel sample accounts for the $34 \%$ "larger content" of magnetite, although a more favorable case would be that both magnetite and hematite account for this excess. The inability to detect hematite using XRD (Fig. 7A)reveals that hematite content is rather less present.

Table 1 Area ratio (row/column) between the integrated band intensities of the bands assigned to Fe-O vibrations of maghemite and magnetite in the ferria gel and magnetite NP samples. Integrated intensities (given in brackets), for each band represented with its maximum frequency: $636 \mathrm{~cm}^{-1}$ (8.328197), $575 \mathrm{~cm}^{-1}$ (12.03922), $637 \mathrm{~cm}^{-1}$ (16.33175), $578 \mathrm{~cm}^{-1}$ (17.56348)

\begin{tabular}{|c|c|c|c|c|c|}
\hline \multirow[b]{2}{*}{ Area ratio } & & \multicolumn{2}{|l|}{ Ferria gel } & \multicolumn{2}{|l|}{ Magnetite NPs } \\
\hline & & $636 / \mathrm{cm}^{-1}(\mathrm{mh})$ & $575 / \mathrm{cm}^{-1}(\mathrm{mn})$ & $637 / \mathrm{cm}^{-1}(\mathrm{mh})$ & $578 / \mathrm{cm}^{-1}(\mathrm{mn})$ \\
\hline Ferria gel & $\begin{array}{l}636 / \mathrm{cm}^{-1}(\mathrm{mh}) \\
575 / \mathrm{cm}^{-1}(\mathrm{mn})\end{array}$ & 1 & $\begin{array}{l}0.69176 \\
1\end{array}$ & $\begin{array}{l}0.50994 \\
0.73717\end{array}$ & $\begin{array}{l}0.47417 \\
0.68547\end{array}$ \\
\hline Magnetite NPs & $\begin{array}{l}637 / \mathrm{cm}^{-1}(\mathrm{mh}) \\
578 / \mathrm{cm}^{-1}(\mathrm{mn})\end{array}$ & & & 1 & $\begin{array}{l}0.92987 \\
1\end{array}$ \\
\hline
\end{tabular}




\subsection{Cytotoxicity of the ferria gel}

Since the ferria gel consists predominantly of interpartically linked magnetite NPs, the material demonstrates a high degree of biocompatibility according to the cytotoxicity study performed on HeLa and MSC cell lines. After $72 \mathrm{~h}$ exposure of ferria gel (17-270 $\mu \mathrm{g} \mathrm{mL}^{-1}$ ) MSC and HeLa cells did not demonstrate any significant decrease in cell viability (Fig. 13A and B). By $72 \mathrm{~h}$ the biggest decrease of MTT conversion, a marker of cell growth inhibition, was $8 \%$ for MSC cells and $18 \%$ for HeLa cells, respectively. Any morphological signs of cell death (not shown) were not observed indicating that even at maximum tested concentrations the ferria gel was biocompatible. Compared to our magnetite cytotoxicity data the magnetite ferria gel was no more toxic and the exposure at equal doses induced similar effects in the cells.

\subsection{Application of the magnetite gel}

Due to the high water-holding capacity and developed microstructure, ferria gels can be used as a magnetic-responsible adsorbent for the removal of heavy metal ions or smart materials for targeted drug delivery. To assess the prospect in these fields, several sorption and desorption experiments were performed using UV-VIS spectroscopy. The sorption of heavy metals was studied for $\mathrm{Cr}^{6+}$ and $\mathrm{Pb}^{2+}$ ions frequently found in wastewater of different technological processes, such as electroplating, metal processing, pigment synthesis and others. ${ }^{33}$ Sorption equilibrium was studied at room temperature at acidic and neutral $\mathrm{pH}$ levels for concentrations ranging from 25 to $200 \mathrm{mg} \mathrm{L}{ }^{-1}$ of $\mathrm{Cr}^{6+}$ and from 20 to $100 \mathrm{mg} \mathrm{L}^{-1}$ of $\mathrm{Pb}^{2+}$ (Fig. 14). According to the sorption kinetics for both metals, the equilibrium is reached within 24 hours after phase mixing. The tested concentration of adsorption isotherms showed the Freundlich-like behavior with maximal sorption capacities at neutral and acidic $\mathrm{pH}$ values of $10 \mathrm{mg} \mathrm{g}^{-1}$ and $26 \mathrm{mg} \mathrm{g}^{-1}$ respectively for chromate ions. In the case of lead ions the sorption capacity by magnetite reaches 44 and $53 \mathrm{mg} \mathrm{g}^{-1}$ in neutral and acidic media, respectively.
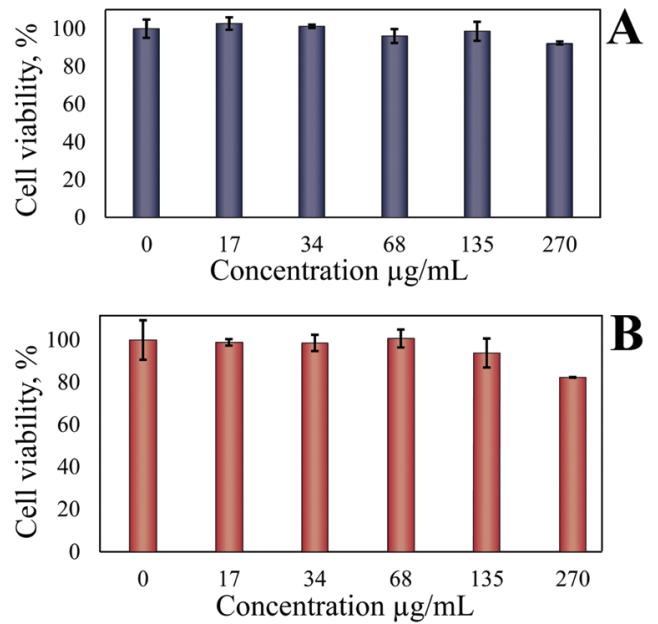

Fig. 13 Cytotoxicity of the ferria gel. The influence of the ferria gel on the viability of MSC (A) and HeLa cells (B). Shown are mean of 3 measurements with standard deviations.
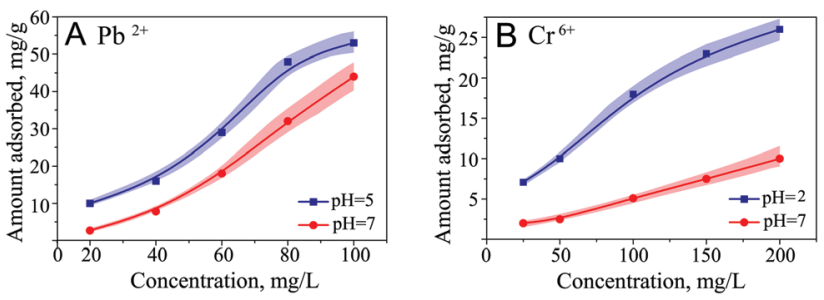

Fig. 14 Adsorption isotherms of (A) $\mathrm{Pb}^{2+}$ and (B) $\mathrm{Cr}^{6+}$ ions on the ferria gel.

Comparing these results with the earlier published ones, ${ }^{34,35}$ it can be concluded that the ferria gel holds great potential as an ion sorbent. The gel sorptive capacity is $225 \%$ higher than that of magnetite nanoparticles. After the adsorption of heavy metal ions ferria gels were regenerated by washing them with $0.005 \mathrm{M}$ of $\mathrm{NaOH}$ or $0.01 \mathrm{M}$ of $\mathrm{HNO}_{3}$ for $\mathrm{Cr}^{6+}$ and $\mathrm{Pb}^{2+}$ ions respectively and reused at least 3 times with a minor decrease of the sorption capacities (91\% for $\mathrm{Cr}^{6+}$ and $82 \%$ for $\mathrm{Pb}^{2+}$ ) (Fig. $2 \mathrm{~S}$, ESI $\dagger$ ). Thus, the ferria gel works well to remove $\mathrm{Cr}^{6+}$ and $\mathrm{Pb}^{2+}$ ions found in wastewater.

The maximum application potential of a ferria gel can be found in the area of drug delivery systems. The high magnetization, thixotropic structure, and fully biocompatible composition of the ferria gel make it a very perspective agent for this aim especially along with the fact that all constituent gel components have approval for parenteral administration by FDA and EMA. To conceptually show this point we have selected intensivelycolored organic dyes, such as methylene blue (MB), to treat methemoglobinemia, ${ }^{36}$ eosin Y (E), an anti-malaria agent ${ }^{37}$ and alizarin S (AS), for bone cancer treatment. ${ }^{38}$ The gels can be doped by direct entrapment of low-molecular weight agents in the course of gelation by the addition of molecule of interest directly to the magnetite hydrosol prior to the gelation procedure. After the addition of propylene oxide and aging, organically-doped gels are formed. Dye-doped gels are represented in Fig. 15.

When the doped gels are transferred to water media, partial release of entrapped molecules occurs, depending on the initial mass fraction of the dye in the doped gel. As the initial loading capacities of the gel can be very high (up to $100 \%$ of dye in terms of dry magnetite), the residual dye content after $\mathrm{MB}, \mathrm{E}$ and AS release is found to be 165,75 and $431 \mathrm{mg} \mathrm{g}^{-1}$ respectively per $1 \mathrm{~g}$

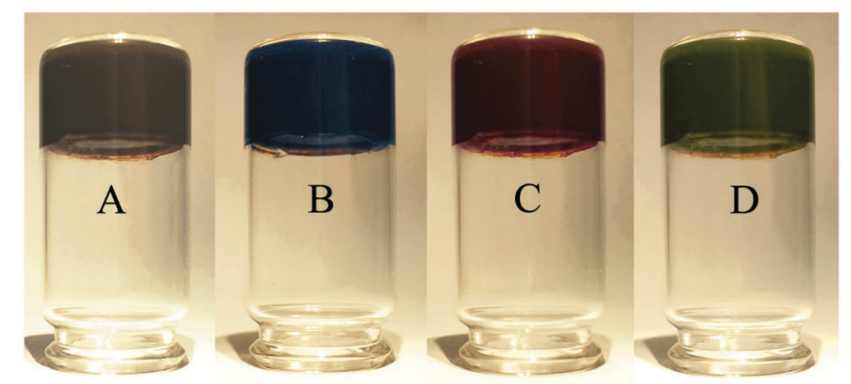

Fig. 15 Visual appearance of dye-doped gels: (A) pure ferria gel, (B) methylene blue, (C) alizarin S, (D) eosin Y. 

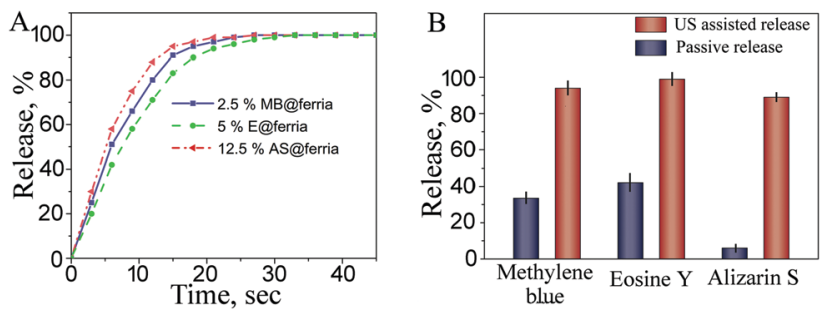

Fig. 16 Release of organic molecules from a gel. (A) Release profile of organic dyes under the influence of US irradiation demonstrates burst mode of release. (B) Release of organic dyes by a passive release extraction of $\mathrm{MB}, \mathrm{E}$ and $\mathrm{AS}$ reaching $33 \%, 42 \%$ and $7 \%$ respectively, US irradiation destroys gel structure stimulating almost full release of the dopant.

of dry magnetite. In comparison with earlier reported data on dye sorption on magnetite NPs, ${ }^{39-41}$ such large sorption capacities cannot be explained by simple electrostatic interactions, but rather a fundamental property of inorganic sol-gel matrices doped by the entrapment procedure, when gelation of the system is carried out in the presence of the dopant to be entrapped. ${ }^{42-44}$ The inner environment of the sol-gel cage is different from that observed in solution, resulting in a stronger interaction of the entrapped species with the cage walls in comparison to that observed in the case of simple adsorption. The doped gel could be used to perform the stimuli-responsive release under the influence of US irradiation. Such a technique is often applied to control the release from soft materials such as lyposomes ${ }^{45,46}$ or hydrogels. ${ }^{47,48}$ Due to the thixotropic nature of the ferria gel, vibrations caused by ultrasound irreversibly destroy the gel structure and promote dopant release. After the immersion of the doped gels into $37 \mathrm{kHz}$ US-bath for 30 seconds, almost full release is observed: the $\mathrm{MB}, \mathrm{E}$ and $\mathrm{AS}$ portions of the dye found in the solution reaches $94 \%, 98 \%$ and $91 \%$ respectively, while the residual quantity is adsorbed on the surface of the magnetite nanoparticles (Fig. 16A and B). Since the US-triggered release of entrapped agents is occurring in a burst mode, it could be concluded that drug loaded ferria gels could be applied for therapeutic scenarios when fast and localized application of large volumes of drugs is needed. These cases involve acute pathologic conditions such as stroke, bleedings or acute localized pain. ${ }^{49-51}$ In these cases a burst release profile in combination with the potential ability to be magnetically localized in a desired area makes the ferria gel a perspective drug delivery agent.

\section{Conclusion}

This work described the structure, behavior and the possible applications of the pure magnetite gel obtained for the first time. The gel was prepared by propylene-oxide mediated gelation of a stable magnetite hydrosol which appeared as a dark-brown magnetic viscous thixotropic material, with up to $94 \%$ mass fraction of a solvent. The dried gel shows a developed nanoarchitecture and textural properties with a specific surface area of $135 \mathrm{~m}^{2} \mathrm{~g}^{-1}$ and a mean pore diameter of $19 \mathrm{~nm}$. Dried gels possess a high coercivity of $65 \mathrm{emu} \mathrm{g}^{-1}$ and superparamagnetic behavior. The gel formation mechanism was investigated by
Raman and IR spectroscopy and found to be mediated by the formation of interparticle $\mathrm{Fe}-\mathrm{O}-\mathrm{Fe}$ bonds with a hematite-like structure. The material demonstrates excellent biocompatibility in tests with HeLa and MSC cell lines in concentrations up to $270 \mu \mathrm{g} \mathrm{mL}^{-1}$. The study has revealed that the ferria gel can be used as an adsorbent for the removal of heavy metal ions with sorption capacities for $\mathrm{Cr}^{6+}$ and $\mathrm{Pb}^{2+}$ ions of up to $26 \mathrm{mg} \mathrm{g}^{-1}$ and $53 \mathrm{mg} \mathrm{g}^{-1}$, respectively. By entrapping of organic molecules in the process of gelation, it is possible to create stimuli-responsive drug delivery systems with a burst release profile under the influence of US irradiation due to its fully biocompatible composition and excellent drug loading capacity.

\section{Conflicts of interest}

There are no conflicts to declare.

\section{Acknowledgements}

This work was supported by Russian Science Foundation, Grant No. 16-13-00041.

\section{References}

1 A. Campanella, O. Holderer, K. Raftopoulos, C. Papadakis, M. Staropoli, M. Appavou, P. Müller-Buschbaum and H. Frielinghaus, Nanotechnology (IEEE-NANO), 2016 IEEE 16th International Conference on, 2016, pp. 446-447.

2 S. F. Chin, A. N. B. Romainor and S. C. Pang, Mater. Lett., 2014, 115, 241-243.

3 X. Xu, H. Li, Q. Zhang, H. Hu, Z. Zhao, J. Li, J. Li, Y. Qiao and Y. Gogotsi, ACS Nano, 2015, 9, 3969-3977.

4 Y. Li, R. Zhang, X. Tian, C. Yang and Z. Zhou, Appl. Surf. Sci., 2016, 369, 11-18.

5 S. A. Meenach, J. Z. Hilt and K. W. Anderson, Acta Biomater., 2010, 6, 1039-1046.

6 Z.-Q. Zhang and S.-C. Song, Biomaterials, 2016, 106, 13-23.

7 N. S. Satarkar and J. Z. Hilt, J. Controlled Release, 2008, 130, 246-251.

8 S. Merino, C. Martn, K. Kostarelos, M. Prato and E. Vazquez, ACS Nano, 2015, 9, 4686-4697.

9 H. Li, G. Go, S. Y. Ko, J.-O. Park and S. Park, Smart Mater. Struct., 2016, 25, 027001.

10 C. Peters, M. Hoop, S. Pané, B. J. Nelson and C. Hierold, $A d v$. Mater., 2016, 28, 533-538.

11 M. Rintoul, S. Torquato, C. Yeong, D. Keane, S. Erramilli, Y. Jun, D. Dabbs and I. Aksay, Phys. Rev. E: Stat. Phys., Plasmas, Fluids, Relat. Interdiscip. Top., 1996, 54, 2663.

12 J. Chatterjee, Y. Haik and C. J. Chen, Colloid Polym. Sci., 2003, 281, 892-896.

13 X. Liu, M. D. Kaminski, Y. Guan, H. Chen, H. Liu and A. J. Rosengart, J. Magn. Magn. Mater., 2006, 306, 248-253.

14 S. Basak, N. Nandi, S. Paul, I. W. Hamley and A. Banerjee, Chem. Commun., 2017, 53, 5910-5913. 
15 M. Breulmann, H. Cölfen, H.-P. Hentze, M. Antonietti, D. Walsh and S. Mann, Adv. Mater., 1998, 10, 237-241.

16 J. Zhang, S. Xu and E. Kumacheva, J. Am. Chem. Soc., 2004, 126, 7908-7914.

17 R. F. Ziolo, E. P. Giannelis, B. A. Weinstein, M. P. O'Horo, B. N. Ganguly, V. Mehrotra, M. W. Russell and D. R. Huffman, Science, 1992, 257, 219-224.

18 M. Babincová, D. Leszczynska, P. Sourivong, P. Čičmanec and P. Babinec, J. Magn. Magn. Mater., 2001, 225, 109-112.

19 J. D. Walker and R. Tannenbaum, Chem. Mater., 2006, 18, 4793-4801.

20 A. E. Gash, T. M. Tillotson, J. H. Satcher Jr, J. F. Poco, L. W. Hrubesh and R. L. Simpson, Chem. Mater., 2001, 13, 999-1007.

21 A. C. Pierre and G. M. Pajonk, Chem. Rev., 2002, 102, 4243-4266.

22 J. W. Long, M. S. Logan, C. P. Rhodes, E. E. Carpenter, R. M. Stroud and D. R. Rolison, J. Am. Chem. Soc., 2004, 126, 16879-16889.

23 A. S. Drozdov, V. Ivanovski, D. Avnir and V. V. Vinogradov, J. Colloid Interface Sci., 2016, 468, 307-312.

24 A. Baral, S. Roy, A. Dehsorkhi, I. W. Hamley, S. Mohapatra, S. Ghosh and A. Banerjee, Langmuir, 2014, 30, 929-936.

25 D. Han, J. Wang and H. Luo, J. Magn. Magn. Mater., 1994, 136, 176-182.

26 O. N. Shebanova and P. Lazor, J. Solid State Chem., 2003, 174, 424-430.

27 Y.-S. Li, J. S. Church and A. L. Woodhead, J. Magn. Magn. Mater., 2012, 324, 1543-1550.

28 M. Hanesch, Geophys. J. Int., 2009, 177, 941-948.

29 D. De Faria and F. Lopes, Vib. Spectrosc., 2007, 45, 117-121.

30 G. V. Jacintho, A. G. Brolo, P. Corio, P. A. Suarez and J. C. Rubim, J. Phys. Chem. C, 2009, 113, 7684-7691.

31 M. Gotić and S. Musić, J. Mol. Struct., 2007, 834, 445-453.

32 V. Petruševski, V. Ivanovski, B. Šoptrajanov and M. Zugik, J. Mol. Struct., 2001, 563, 329-333.

33 M. Barakat, Arabian J. Chem., 2011, 4, 361-377.
34 M. Kumari, C. U. Pittman and D. Mohan, J. Colloid Interface Sci., 2015, 442, 120-132.

35 V. Mikhaylov, T. Maslennikova and P. Krivoshapkin, Mater. Chem. Phys., 2017, 186, 612-619.

36 J. n. Clifton and J. B. Leikin, Am. J. Ther., 2003, 10, 289-291.

37 T. Gebru, B. Mordmüller and J. Held, Antimicrob. Agents Chemother., 2014, 58, 7398-7404.

38 C. Fotia, S. Avnet, D. Granchi and N. Baldini, J. Orthop. Res., 2012, 30, 1486-1492.

39 B. S. Inbaraj and B. Chen, Bioresour. Technol., 2011, 102, 8868-8876.

40 T. Madrakian, A. Afkhami and M. Ahmadi, Spectrochim. Acta, Part A, 2012, 99, 102-109.

41 S. Giri, N. Das and G. Pradhan, Colloids Surf., A, 2011, 389, 43-49.

42 A. Slama-Schwok, M. Ottolenghi and D. Avnir, Nature, 1992, 355, 240.

43 M. Pagliaro, R. Ciriminna and G. Palmisano, Chem. Soc. Rev., 2007, 36, 932-940.

44 D. Avnir, Acc. Chem. Res., 2013, 47, 579-592.

45 A. L. Klibanov, T. I. Shevchenko, B. I. Raju, R. Seip and C. T. Chin, J. Controlled Release, 2010, 148, 13-17.

46 A. Schroeder, R. Honen, K. Turjeman, A. Gabizon, J. Kost and Y. Barenholz, J. Controlled Release, 2009, 137, 63-68.

47 H. Epstein-Barash, G. Orbey, B. E. Polat, R. H. Ewoldt, J. Feshitan, R. Langer, M. A. Borden and D. S. Kohane, Biomaterials, 2010, 31, 5208-5217.

48 N. Huebsch, C. J. Kearney, X. Zhao, J. Kim, C. A. Cezar, Z. Suo and D. J. Mooney, Proc. Natl. Acad. Sci. U. S. A., 2014, 111, 9762-9767.

49 X. Huang and C. S. Brazel, J. Controlled Release, 2001, 73, 121-136.

50 A. S. Drozdov, K. V. Volodina, V. V. Vinogradov and V. V. Vinogradov, RSC Adv., 2015, 5, 82992-82997.

51 H. Zhao, R. M. Sapolsky and G. K. Steinberg, J. Cereb. Blood Flow Metab., 2006, 26, 1114-1121. 